\title{
Sobre el concepto bíblico del initium et finis mortis en el claustro de San Marcos de León
}

Fernando Llamazares Rodriguez $(\dagger)$ Universidad de Castilla-La Mancha

RESUMEN:

En el presente artículo se efectúa un análisis detenido de la iconografía vetero y novotestamentaria del claustro de San Marcos de León, de época renacentista, donde se desarrolla un programa en torno al inicio y final de la muerte, en relieves escultóricos e inscripciones latinas.

\section{PALABRAS CLAVE:}

San Marcos de León, claustro; muerte; relieve; Biblia.

\section{ABSTRACT:}

In the present issue it is analyzed the iconography of the Old and New Testament of San Marcos de León cloister, Renaissance style, where a programme about the beginning and the end of the death is developed in sculptorical reliefs and Latin inscriptions.

KEY WORDS:

San Marcos de León, cloister; death; relief; Bible. 
El convento de San Marcos de León fue casa matriz de la Orden de Santiago en el reino de León. Enclavado sobre el Camino de Santiago, junto al río Bernesga, a la salida de la ciudad de la ciudad de León, tuvo orígenes medievales. De aquellos tiempos antiguos nada queda, pues se comenzó una nueva construcción a partir del Capítulo celebrado en Valladolid en 1513. Si bien su principal fábrica pertenece a un primer renacimiento, las obras no finalizaron hasta el siglo XVIII ${ }^{1}$. Tanto en la fachada principal, en su sección del siglo xvI, como en las dos hornacinas laterales que enmarcan la portada de la iglesia, la antesacristía con la escalera de subida al claustro, la sacristía y partes del claustro con decoración de medallas, se ofrecen, en escultura pétrea, estupendos programas iconográficos renacentistas ${ }^{2}$. Tanta labor en piedra precisó de un buen número de escultores, algunos de singular valía, encabezando la lista Juan de Juni ${ }^{3}$,

\footnotetext{
Sobre este edificio puede consultarse, principalmente, entre otros: Gaspar Melchor de Jovellanos, "A Don Antonio Ponz, Carta II", Cartas a varias personas, Habana, 1848 (reed.: Madrid, 1952, pp. 276-280); Antonio Ponz, reprodujo la mayor parte de esta carta en su "Carta sexta", Viage de España, t. XI, Madrid, 1787, pp. 243-258; José María QuADRADo, Recuerdos y bellezas de España. Asturias y León, Madrid, 1855 (reed.: Salinas, Asturias, 1977, pp. 552-559); Eloy DiAz-JimÉnEZ y MoLLEDA, Historia del Museo Arqueológico de León. Apuntes para un catálogo, Madrid, 1920; Manuel Gómez-MoReno, Catálogo Monumental de España. Provincia de León (1906-1908), Madrid, 1925, pp. 293-301; Waldo Merino RuBIo, «La arquitectura hispano flamenca en San Marcos», Arquitectura hispano flamenca en León, León, 1974, pp. 199-235; M. ${ }^{a}$ Dolores Campos SÁncheZ-BordoNA, Juan de Badajoz y la arquitectura del renacimiento en León, León, Universidad de León, 1993; Íd., El antiguo Convento de San Marcos de León, sede del Museo de León (Guía breve), León, 1997; Fernando Llamazares Rodríguez, San Marcos de León, esplendor del primer renacimiento, León, 1996; ÍD., "La portada del exconvento de San Marcos de León. Ingreso al Aula Dei», en Jesús M. a Nieto Iвáñez (coord.), Lógos Hellenikos. Homenaje al profesor Gaspar Morocho Gayo, León, Universidad de León y Sociedad Española de Estudios Clásicos, 2003, pp. 857-865; M. ${ }^{a}$ Dolores CAMPOS SÁNchez-Bordona y Aránzazu Oricheta García, «El Convento de San Marcos de León. Nuevos datos sobre el proceso constructivo en el siglo xvI", Academia. Boletín de la Real Academia de Bellas Artes de San Fernando, n. ${ }^{\circ}$ 86, Madrid, 1998, pp. 233-271.

2 Sobre el conjunto de la antesacristía, con la escalera de acceso al claustro alto y la sacristía, puede consultarse Fernando Llamazares Rodríguez, "Las piedras hablan. Inter sacrarium et altare. El ejemplo de la iglesia de San Marcos de León", Norba. Revista de arte, n. ${ }^{\circ} 33$, Cáceres, 2014 (en prensa).

3 En torno al año 1535 Juni llegaría a León y aquí se avecindaría hasta 1540 que se dirige a Salamanca, para pasar definitivamente a Valladolid, probablemente en
}

acompañado de otros como Juan de Angés el Viejo $^{4}$ o Esteban Jamete. Así mismo, hay que tener en cuenta la participación de entalladores como Guillermo Doncel ${ }^{6}$.

En el ángulo N.E., del claustro, en la capilla del Nacimiento, y en el tramo anterior a este espacio de la crujía de Levante se desarrolla todo un programa bíblico, en torno al principio y final de la muerte que se manifiesta en ménsulas, muros, cartelas, bóvedas y retablo pétreo que constituye el objeto de este estudio. Las obras de esta zona del claustro se llevaron a cabo durante la tercera década del siglo xvi.

La obra de Juan de Juni se manifiesta claramente en el relieve del retablo pétreo del $\mathrm{Na}$ cimiento de Jesús. Si no es la primera producción de Juni en San Marcos, si al menos de las primeras, por tanto se realizaría en torno a 1535-1536. Sus altos valores plásticos no han pasado inadvertidos a los diversos autores que han escrito sobre él. El primero en llamar la atención sobre este singular conjunto fue don Manuel Gómez-Moreno, que definió esta repre-

1541, y aquí permaneció hasta su muerte en 1577. A pesar de su asentamiento en la capital del Pisuerga, no perdió los lazos con León, y desde allí siguió atendiendo encargos para esta ciudad y provincia. Gran parte de la obra en piedra realizada por Juni en San Marcos está estudiada, magistralmente, por Manuel ARIAS Martínez, "Revisando a Juan de Juni en San Marcos de León. Fuentes y modelos», Boletín de la Real Academia de Bellas Artes de la Purísima Concepción, n. ${ }^{\circ}$ 43, Valladolid, 2008, pp. 9-34.

4 El escultor francés Juan de Angés, desde los primeros días del mes de enero de 1534 hasta el año 1576, se documenta su labor en León. En 1578 ya había muerto, pues su hijo homónimo reclama el dinero que se le estaba debiendo del retablo de Palanquinos. Véase Fernando Llamazares Rodríguez, "Juan de Angés el Viejo y su obra escultórica en Palanquinos», Tierras de León, n. ${ }^{\circ}$ 75, 1989, pp. 123 y 124.

5 Jamete, natural de Orleans, pasó algún tiempo en León, donde trabajó en piedra y madera en San Marcos, según se recoge en el proceso habido contra él en 1557. Consúltese Jesús Dominguez Bordona, Proceso inquisitorial contra el escultor Esteban Jamete, Madrid, 1933, p. 25. Arias Martínez, en "Revisando a Juan de Juni», p. 11, platea como hipótesis su llegada a España en 1535 para dirigirse en primer lugar a León, a donde tras pasar por varios lugares, volvería para trabajar como escultor en San Marcos, y a esa misma llegada y año a León vincula la venida del también francés Juan de Juni a esta ciudad.

6 Guillermo Doncel, de origen francés, llegaría a León en los primeros años de la tercera década del siglo xvI, y aquí desarrollaría su actividad hasta 1556. Véase Gloria CARRIZo SAINERo, "Escultura, pintura y orfebrería del Renacimiento», en Manuel VALdÉs Fernández (coord.), Historia del Arte en León, León, Diario de León, Junta de Castilla y León y Universidad de León, 1990, p. 205. 


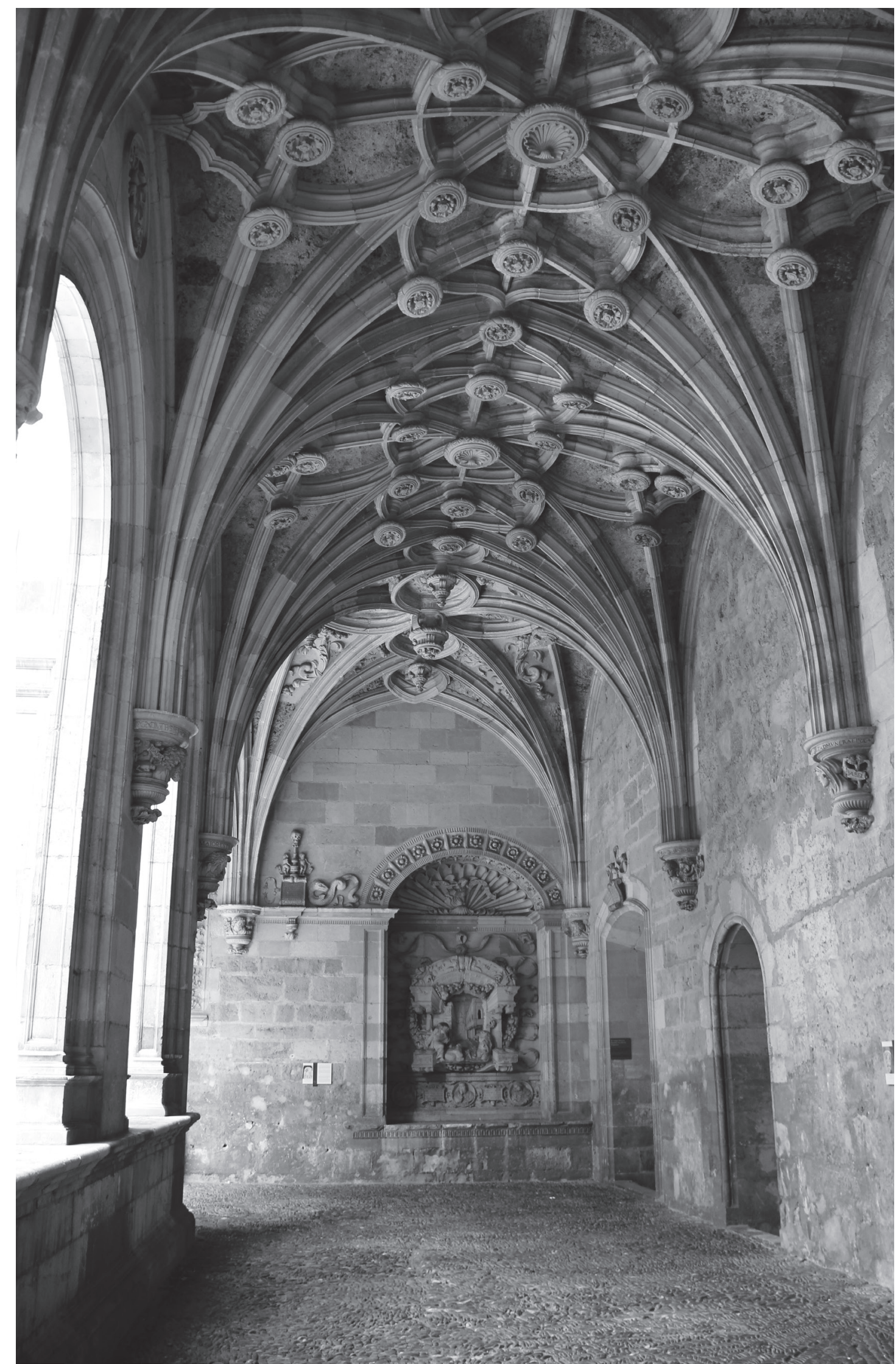

Fig. 1. Claustro de San Marcos de León, últimos tramos de la crujía del lado de levante y ángulo noreste. Juan de Badajoz, hacia 1535-1537. 


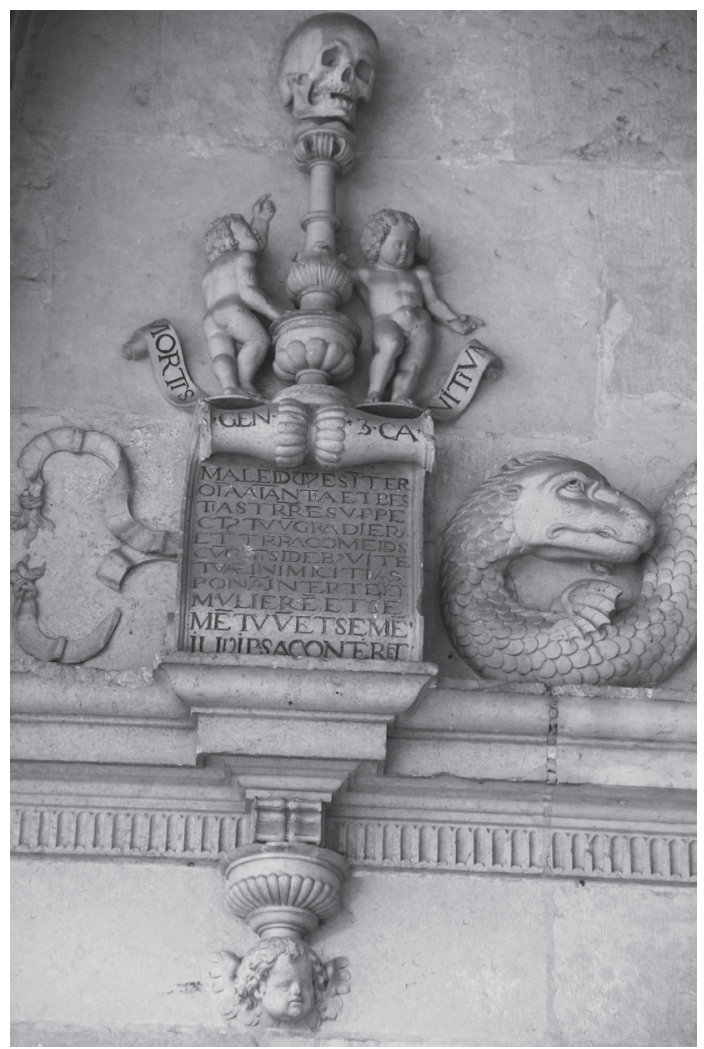

Fig. 2. Claustro de San Marcos de León. Mortis initivm en el muro noreste. Hacia 1535-1537.

sentación de la Natividad (incluida en un monumental edificio puesto en perspectiva, rodeado de frutas, niños, cintas y otros adornos, que ha padecido lamentables destrozos, particularmente en la composición de la escena) como una obra de Juni, quien aquí revela sus dotes singulares de fogosidad, delicadeza y pintoresquismo. ${ }^{7}$ Martín González afirmó que Juni aquí se presenta con un estilo plenamente hecho e impregnado de elementos clásicos e italianos renacientes, y en cuanto al estilo, afirmaba que es de un dinamismo desbordante y de un pathos lleno de dramatismo. ${ }^{8}$

El principal estudio sobre este conjunto se debe a Manuel Arias Martínez, quien centra la composición de este relieve en fuentes de grabados. Esta obra está claramente vinculada al mismo tema del retablo pétreo portugués de Nuestra Señora de la Pena, en Sintra, realizado por Nicolás de Chanterenne, lo cual pone

\footnotetext{
Gómez-Moreno, Catálogo monumental de España. León, p. 298.

8 Juan José Martín GonzÁlez, Juan de Juni. Vida y obra,
} Madrid, 1974, p. 91. de manifiesto que ambos conjuntos tienen una misma fuente gráfica. No obstante, hay alguna diferencia notable entre estos dos relieves. El fondo arquitectónico que se ofrece en el modelo de San Marcos no aparece en el portugués. Como se ha apuntado, este fondo arquitectónico está tomado de una estampa de Bramante. ${ }^{9}$ La disposición de este tipo de escenario de la Natividad con perspectivas arquitectónicas, como afirma Arias Martínez, se repite, casi abrumadoramente, en composiciones pintadas o grabadas de Jean Gourmont; y este mismo esquema se recoge en una estampa de Georges Reverdy ${ }^{10}$.

A Juni creemos que también le pertenecen las medallas de los tres Profetas de la predela de este retablo, que no se conservan en demasiado buen estado.

A Juan de Angés y a su círculo le corresponderá todo el repertorio renacentista que se halla en las ménsulas y medallas del claustro, cuyos estilemas se vinculan claramente con la obra la sacristía, documentada como suya ${ }^{11}$. Siguiendo el modelo documentado de Juni de la cabeza de Jesús en la silla prioral, se efigia a Set, Lamek e Isaías, evidenciando de este modo la influencia del gran maestro sobre autores como Angés. La realización de toda esta obra escultórica se llevaría a cabo entre los años 1535-1537, pues las bóvedas posteriores a este conjunto marcan la data de 1538.

\section{Initium mortis}

La narración sobre el inicio de la muerte tiene su origen en el pecado original. En el claustro de San Marcos, se recogen tres aspectos de la caída, narrada en el capítulo tercero del Libro del Génesis. Dos ménsulas del tramo de la crujía de levante efigian en bustos a Eva y Adán, identificados por sendas epigrafías: Eva y $A D A N$. Eva se halla en el Paraíso, insinuado por algunos árboles, y entra en diálogo con la serpiente parlante con cabeza humana femenina que se enrosca en el árbol y le dice: cvr praecepit bobis [sic] Devs vt non comederitis / ex omni ligno paradisi Gene[sis] 3 (Gn 3, 1). Dos

\footnotetext{
Fernando MARías, El largo siglo XVI, Madrid, 1989, p. 318. 10 Arias Martínez, "Revisando a Juan de Juni», pp. 14-15. 11 Sobre la obra de Angés en la sacristía, véase CAMPos SÁncheZ-Bordona y ORICHETA GARCía, «El Convento de san Marcos de León», p. 247.
} 
filacterias sobre el busto recogen la respuesta de la mujer: DE FRVCTV VERO LIGNI QVOD EST IN MEDIO PARADISI PRAECEPIT NOBIS DEVS NE COMEDEREMVS $(\mathrm{Gn} 3,3)$. Tras sucumbir y consumarse el pecado por incitación de la serpiente, se pasó de la incorruptibilidad del hombre al perecer por la muerte: "Porque Dios creó al hombre para la incorruptibilidad, le hizo de su misma naturaleza; mas por envidia del diablo entró la muerte en el mundo, y la experimentan los que le pertenecen" (Sb 2, 23-24). Pasaje clave para el misterio de la redención en el cristianismo, recordado por san Pablo en una de sus Epistolas: "Por un solo hombre entró el pecado en el mundo y por el pecado, la muerte, y así la muerte alcanzó a todos los hombres, por cuanto todos pecaron" (Rm 5, 12).

Para el pueblo israelita, la serpiente era un ser astuto y peligroso, pero aquí encierra un trasfondo polémico, pues los cananeos la adoraban como imagen de la vida, de la fecundidad y de la sabiduría. Por tanto, para los israelitas era símbolo de la idolatría pagana, y dejarse seducir por la serpiente era apostatar de la fe en Dios y aceptar el culto idolátrico. Como conclusión, la presencia de la serpiente en el relato bíblico no es algo aleatorio sino que obedece a planteamientos espirituales y religiosos de la historia del pueblo de Israel y de su constitución como pueblo. El fruto prohibido, según la narración bíblica, fascinaba, pues era bueno, hermoso y deseable; por ello fue comido primero por la mujer y posteriormente por el varón. A continuación de haber comido la mujer, se perpetra el pecado de Adán y la búsqueda de él, por parte de un Dios antropomorfo, para interrogarle si había comido del árbol prohibido: ADAN VBI ES (Gn 3, 9). Esta expresión inquisitiva está escrita sobre el busto de Adán, que queda enmarcado por árboles que aluden al Paraíso. Su respuesta, se halla a ambos lados del personaje: vocem tvam Domine avdivi / et timvi ${ }^{12}$ (Gn 3, 9). Adán ha oído la pregunta de Dios y le invade el temor, pues ha tomado conciencia de su desnudez o lo que es lo mismo, de su pecado. Como consecuencia se produce la sentencia de la primera pareja y ambos son expulsados del Paraíso.

Tras la consumación del pecado original y como consecuencia de haber seducido a la mu-

12 El lapicida, en este versículo, enmarañó la grafía, por lo que me fue necesario acudir a mi buen amigo el doctor don Lorenzo Martínez Ángel, para que me interpretara esta epigrafía, por lo que le expreso mi gratitud. jer para comer del árbol prohibido, Yahvé maldijo a la serpiente, cuyas palabras se reproducen en una cartela sobre un entablamento, en el ángulo noreste. Dice así: MALEDICTUS ES INTER / OMNIA ANIMANTIA ET BES/TIAS TERR[A]E SVPER PE/ CTVS TVVM GRADIERIS / ET TERRAM COMEDES / CVNCTIS IDIEBVS (SIC) VIT[A]E TVAE INIMICITAS / PONAM INTER TE ET / MVLIEREM ET SE/MEN TVVM ET SEMEN / ILLIVS IPSA CONTERET (Gn 3, 14-15). A la derecha de la cartela se efigia la imagen de la serpiente. En este relato metafórico se condena a la serpiente a arrastrarse sobre su vientre como castigo por la inducción al pecado. Es una explicación popular de un fenómeno natural. Asimismo, hemos de interpretar tanto los dolores del parto que padece la mujer como el trabajo del hombre en la tierra como un castigo ${ }^{13}$. Esta hostilidad que aquí se marca entre la serpiente y la mujer, incluye también, en el mismo sentido, al hombre y al diablo, anunciando la victoria final del hombre. En este texto, denominado también como Protoevangelio, se ha creído ver el anuncio de la salvación, esbozándose la interpretación mesiánica, uniendo a la presencia del Mesías con la de su Madre. Sobre la cartela dos putti enmarcan una columna ajarronada, uno con su mano izquierda señala una calavera que remata esta columna. Bajo ellos, una filacteria dice: MORTIS / INITIVM. La cartela enrollada, bajo los dos putti en la zona superior, dice: ${ }_{G E N}[E-$ $S I S] \cdot / \cdot 3 \cdot C_{C A}[P I T V L V M] \cdot(\mathrm{Gn} 3,3)$, referido al texto anterior. Este inicio de la muerte responde a la prohibición divina de comer del árbol del centro del paraíso so pena de muerte: "Del fruto del árbol que está en medio del jardín, ha dicho Dios: no comáis de él, ni lo toquéis, pues moriréis" ( $\mathrm{Gn}, 3,3)$.

Sobremontando la piedra clave del arco de la puerta de comunicación de la iglesia con el claustro, escoltada por las dos ménsulas de los Primeros Padres, se lee el siguiente texto, alusivo al primer pecado y a su perpetuación entre todos sus descendientes: PATRES NOSTRI / PECCAVERVNT ET / NON SVNT ET NOS INI/QVITATES EORVM / PORTAVIMVS (Lam 5, 7).

Tras el pecado original, por el que se perdió la intimidad con Dios, se empieza a escribir la historia de la humanidad: "Conoció el hombre a Eva, su mujer, la cual concibió y dio a luz a Caín, y dijo: «He adquirido un varón con el

Estos conceptos están desarrollados por Herbert HAAG, "L'histoire biblique des origines aujourdui", en HAAG, Hass y Hürzeler, Biblie et évolution, Paris, Mame, 1964. 
favor de Yahved" (Gn 4, 1). Eva se convierte ahora en madre de un varón y se muestra por ello exultante. El busto de Caín se halla en la esquina final del claustro noreste, compartiendo espacio con Lamek, de quien trataremos más tarde en el lugar que cronológicamente le corresponde. Caín, con un rostro de mirada fiera, barba abundante y ondulada y largos cabellos agitados por el viento, queda identificado por un rótulo colgado de un arbusto que dice: CAYN. Sobre la ménsula corre la siguiente inscripción: MAIOR EST INIQVITAS MEA QVAM VT VENIAM MEREAR (Gn $4,13)$. En este texto, Caín se lamenta de su desgracia y se queja a Yahvé por haberle condenado a una pena enorme para poder ser soportada, pero no pronuncia ni una sola palabra de arrepentimiento. Esta condena es consecuencia del fratricidio: "Yahved dijo a Caín: «¿Dónde está tu hermano Abel?» Contestó: «No sé. ¿Soy yo acaso el guarda de mi hermano?» Replicó Yahved: "¿qué has hecho? Se oye la sangre de tu hermano clamar a mí desde el suelo. Pues bien, maldito seas, lejos de este suelo que abrió su boca para recibir de tu mano la sangre de tu hermano. Aunque labres el suelo, no te dará su fruto. Vagabundo y errante serás en la tierra»" (Gn 4, 9-12).

Abel, ocupa la ménsula del tramo anterior a la de Eva. "Volvió a dar a luz (Eva) y tuvo a Abel, su hermano. Fue Abel pastor de ovejas y Caín labrador" (Gn, 4, 2). Abel se efigia joven e imberbe, y a ambos lados de su busto se sitúa el rebaño de ovejas, dos de ellas ramonean la hierba apaciblemente junto a un árbol. Aquí se nos ofrece el personaje como pastor que cuida de su ganado. Una cartela junto al busto, colgada de un arbolito a la que se encaraman dos ovejas para alcanzar sus ramas, lo identifica: $A B E L$. Sobre el busto, un epígrafe recoge el siguiente texto: RESPEXIT DOMINVS AD ABEL ET AD MVNERA EIVS GE[NESIS] 4 (Gn 4, 4). Dios se ha complacido en el pastor Abel y en la oblación de los primogénitos de su rebaño, en contraposición a la ofrenda de Caín el labrador con los frutos de la tierra. Como consecuencia, surge la ira de Caín, a quien Yahvé pregunta: “¿Por qué andas irritado y por qué se ha abatido tu rostro? ¿No es cierto que si obras bien, podrás alzarlo? Mas, si no obras bien, a la puerta está el pecado acechando como fiera que te codicia y a quien tienes que dominar.» Caín dijo a su hermano Abel: "vamos afuera" y cuando estaban en el campo se lanzó Caín contra su hermano Abel y lo mató" (Gn 4, 6-8).
Abel es la primera figuración veterotestamentaria de Cristo. Tendrá su equivalente en Jesús, el Buen Pastor; el ofrecimiento de las primicias en el Antiguo Testamento; en Jesucristo, como "Primogénito de toda creación"; el cordero inmolado, en el "Cordero de Dios"; el inocente muerto por el odio de Caín, en el "Crucificado inocente". La sangre del justo Abel clamó al cielo en demanda de expiación, como la sangre de Cristo también clamó al cielo para obtener la reconciliación.

Entre la descendencia de Caín se halla Lamek. Como se ha indicado, la ménsula que ocupa Caín se compartía con el busto de Lamek, separados ambos por una cartela que hace relación al segundo. La representación de este personaje, flanqueado de árboles, en uno de los cuales cuelga una cartela que recoge su nombre: $\angle A M E C H$. Muestra un rostro cargado de tristeza y ofrece unos cabellos y barba ondulados. La cartela central entre los dos personajes tiene el siguiente texto: QVONIAM OCCI/DI VIRVM IN/ VVLNVS / MEVM ET ADOLES/CENTVLVM (Gn 4, 23). Aquí se muestra claramente la maldad creciente de los sucesores de Caín.

El ciclo del Génesis se cierra con la presencia de Set. "Adán conoció otra vez a su mujer y ella dio a luz un hijo que le puso por nombre Set" (Gn 4, 25). La ménsula del lado norte, paralela a la de Adán, está reservada a él. Ofrece rostro de actitud concentrada, con abundante cabellera y barba rizada, en medio de un espacio naturalista, ambientado en su lado izquierdo con una pareja de bueyes que labran la tierra arrastrando un arado junto a un campo arbolado y, en su lado derecho, entre abundante vegetación, en una cartela pendiente de un árbol se lee su nombre: SETH. Sobre el busto corre este rótulo: POSVIT MIHI DEVS SEMEN ALIVD PRO ABEL QVEM OCCIDIT CAYN $(\mathrm{Gn} 4,25)$. Claramente, era necesario establecer una nueva descendencia que no fuera la de Caín. Por ello, Yahvé concedió a la primera pareja otro varón justo en el lugar de Abel.

\section{Finis mortis}

Cerrado el ciclo del Génesis, otra ménsula en frente de la que efigia a Abel, presenta al profeta Isaías que anuncia ya el capítulo del final de la muerte, y el advenimiento de la nueva vida por medio de la Salvación. El busto de Isaías, barbado y con largos cabellos ondulados, muestra un rostro cargado de preocupación. Es 
la expresión gestual del que clama contra el pueblo ingrato, elegido por Dios. A su mano derecha hay dos árboles $\mathrm{y}$, pendiente de uno, cuelga una cartela con su nombre: ESAIAS. Un buey recostado, cierra este espacio. A la mano izquierda, un asno come en su pesebre y al fondo hay dos arbolitos. Es una perfecta representación iconográfica del texto latino que figura sobre el profeta: COGNOVIT BOS POSSESOREM SVVM ET ASINVS PR[A]ESEPE DOMINI SVI (Is 1, 3). El pueblo israelita no conoce, y por ello no comprende, a su Dios cuando hasta el buey y el asno saben quiénes son sus dueños y quién les da de comer. En parecidos términos, se manifestará también el profeta Jeremías: "Hasta la cigüeña en el cielo conoce su estación y la tórtola, la golondrina o la grulla observan la época de sus migraciones. Pero mi pueblo ignora el derecho de Yahved" (Jr 8, 7).

El texto de Isaías, ilustrado con la representación del buey y la mula, se ha tomado como el precedente veterotestamentario de los dos animales que se introducirán en la iconografía de la cueva de Belén con motivo del nacimiento de Jesús. En la versión de la Biblia de los $L X X$, al hacer la traducción del profeta Habacuc en su capítulo tercero, versículo segundo, se lee: "Te manifestarás en medio de dos animales". Es una incorrecta traducción del texto original griego, pero así, junto a Isaías y Los Evangelios apócrifos de la Natividad (Ps Mateo, XIV), es la fuente literaria de la tradición de los dos animales del pesebre de Belén. La iconografía plástica del buey y la mula en la cueva o establo de Belén se puede rastrear a lo largo de toda la historia a partir del siglo iv, donde hay ya ejemplos, como el de una galería del cementerio de San Sebastián, en Roma, donde ambos animales están arrodillados ante el niño Jesús, envuelto en pañales. En el busto de Isaías de San Marcos de León, se puede observar que el profeta ladea el rostro y dirige su mirada hacia el altar de la Natividad, que se halla en el muro noroccidental, vinculando, de este modo, su presencia física y profética con la realidad de la venida del Mesías, hecho hombre, que se manifiesta en el retablo fabricado en piedra.

En la capilla del ángulo noreste se abre una hornacina en el muro que se cubre con un retablo pétreo tripartito. A ambos lados, dos jambas cajeadas sostienen un arco rebajado que, en su rosca e intradós, inserta casetones con motivos florales en sus centros. Sobre la mesa del altar, surge el retablo del Nacimiento de Jesús,

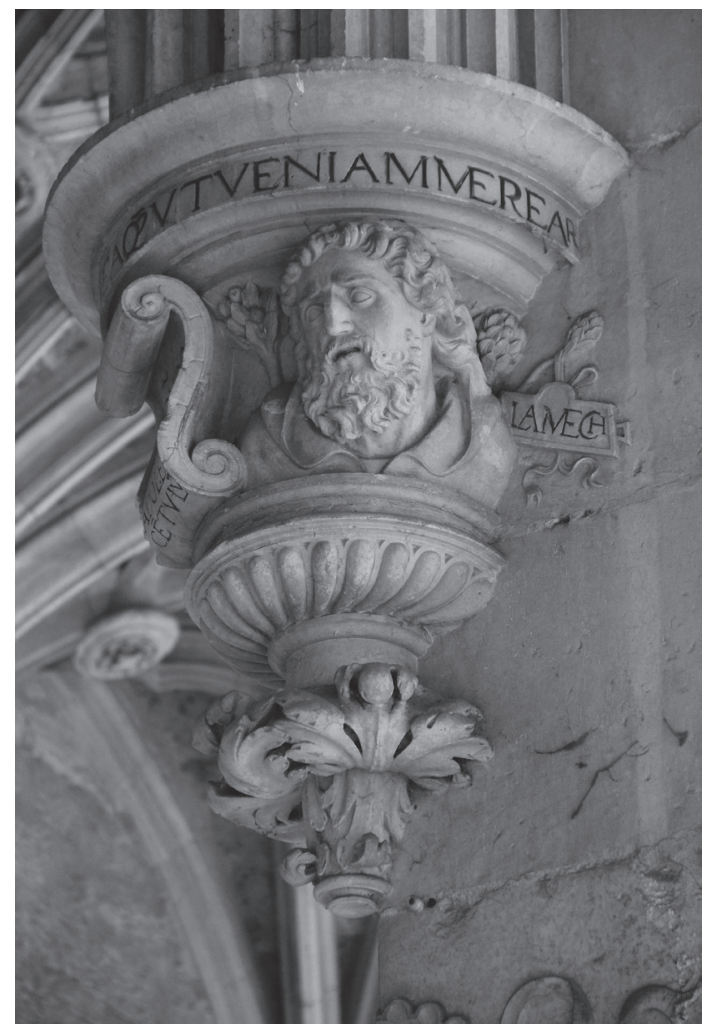

15

Fig. 3. Claustro de San Marcos de León. Ménsula con inscripciones y busto de Lamek. ¿Juan de Angés el Viejo?, hacia 1535-1537.

que consta de predela, cuerpo único y ático. En aquella se efigian en tres medallas los bustos de los profetas Jeremías, Isaías y Daniel, identificados por rótulos y dos tarjetas que incluyen textos de Jeremías y de Daniel, escoltando a Isaías. En el cuerpo único se escenifica la $\mathrm{Na-}$ tividad y, en el tímpano del ático, una venera incluye en su centro un ángel tenante de filacteria con el cántico del Gloria.

La predela, a modo de sostén, basa su mensaje en la profecía mesiánica. En este caso el profeta Isaías permanece silente en el centro. En el lado de la epístola se efigia a Jeremías, cuyo esquema compositivo es el mismo que Juni aplicó al apóstol Simón, en la sillería coral de la propia iglesia de San Marcos. Su cabeza gira con fuerza hacia su lado izquierdo y con su brazo derecho amarra el manto que discurre por su hombro y brazo izquierdo. El rostro se halla bastante deteriorado. Un rótulo, en una tarjetilla que sostiene con su mano izquierda, lo identifica en dos renglones: HIERE/MIAS. Junto a él, una cartela recoge el versículo que dice: CREAVIT DOMINVS NO/VVM SVPER TERRAM / FOEMINA CIRCVM/DABIT VIRVM HI[EREMIAS] 31 (Jr 31, 22). Este versículo es de gran alcance mesiánico y expre- 


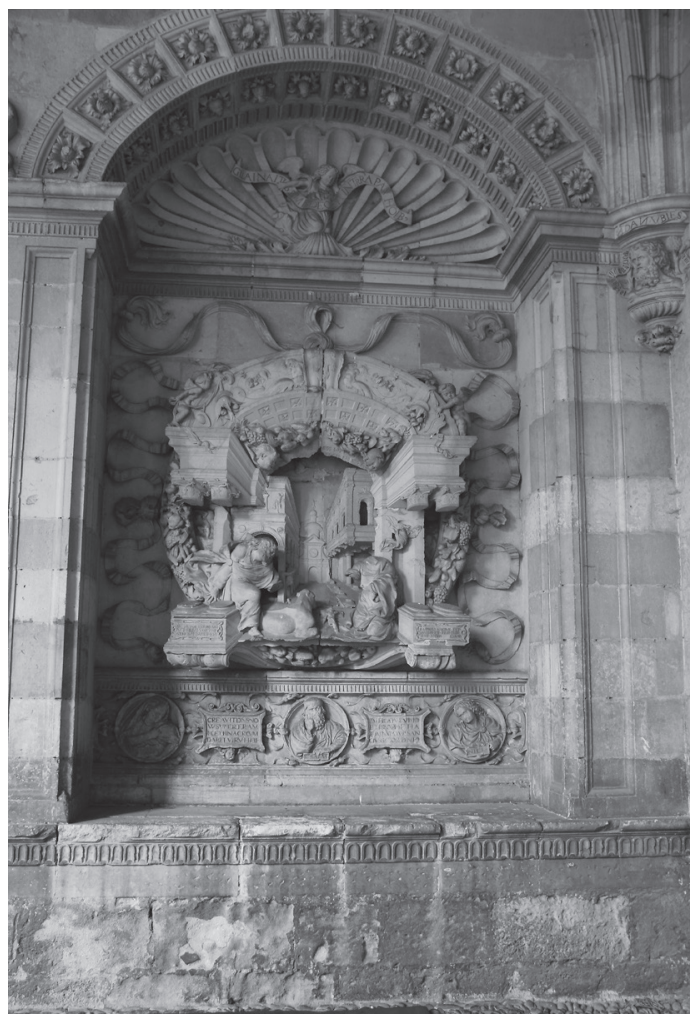

Fig. 4. Claustro de San Marcos de León. Retablo del Nacimiento, en el ángulo noreste. Juan de Juni, hacia 1535-1536.

sa la reanudación de las relaciones de amor entre Israel, como mujer infiel, y su esposo Yahvé.

En el centro de la predela, preside el profeta Isaías, cuyo relieve se halla un tanto deteriorado. Es un anciano de barba larga, en actitud pensativa. La cabeza se cubre con un gorro, tipo pasamontañas. Su mano izquierda porta una tarjeta donde lleva inscrito el nombre: ESAIAS. No le acompaña ningún texto profético de su estro en esta zona. Se ha preferido dejarlo para la escena del Nacimiento. Cierra esta tríada en torno a la venida del Mesías la figura de Daniel, a quien se representa joven, imberbe y de larga cabellera. Se cubre con un manto abotonado con un broche. Sus manos sujetan una cartela en la que figura su nombre: $D A /$ NIEL. Una tarjeta junto a él, incluye un texto: IMPLEATVR VISIO / ET PROPHETIA / ET VNGATVR SAN/CTVS S[AN]CTORVM D[A] NI[ELIS] 9 (Dn 9, 24).

Este versículo, donde se pide sellar visión y profecía para ungir al Santo de los Santos, forma parte de la profecía de las setenta semanas de años (490 años) y, que una vez finalizadas, anuncia la llegada del reino de Dios y "será muerto un mesías" (Dn 9, 26). En estos momentos históricos vividos por Daniel, se perciben ya las ideas de un Mesías y Salvador. Como se ha afirmado: "en Daniel, la figura del Enviado de Dios, al cual compete actuar aquí abajo el reino de Dios, asume una colaboración totalmente nueva. No es ya simplemente el «Rey y el Hijo de David", sino que es descrito bajo la figura misteriosa del "Hijo del Hombre», que viene sobre (o con) las nubes del cielo. Estamos frente a un mesianismo trascendente, que prepara directamente el camino al Nuevo Testamento"". ${ }^{14}$

El cuerpo único del retablo pétreo, ya estudiado formalmente, escenifica la Natividad. El niño Jesús, desnudo, se halla tendido en el suelo. Cercano a él se sitúa el buey tumbado. A su izquierda se coloca María, arrodillada; y a la izquierda, san José con una rodilla en tierra. Esta escena es el comienzo de la Redención, el final de la muerte y el anuncio de la nueva vida. En el basamento de las columnas, en la del lado del evangelio, hay un epígrafe con texto del profeta Isaías: PARVVLVS NATVS EST / NOBIS ET FILIVS DATVS / EST NOBIS ESAIE (Is 9, 5). Este texto tiene su paralelo en el mismo profeta, en el capítulo 7, versículo 14, en la señal del Emmanuel: "Pues bien, el Señor mismo va a daros una señal: he aquí que una doncella está encinta y va a dar a luz un hijo, y le pondrá por nombre Emmanuel". El versículo aquí recogido, sobre un niño nacido para nosotros y un hijo que también para nosotros se nos da, hay que cerrarlo, para una mejor comprensión, con la cita bíblica completa del mismo que dice: "Estará el señorío sobre su hombro, y se llamará su nombre "Maravilla de Consejero", "Dios Fuerte», "Siempre Padre», "Príncipe de la Paz»". Estos títulos, como se ha afirmado: "son comparables a los protocolarios que se preparaban para el Faraón en su coronación. El hijo del linaje real tendrá la sabiduría de Salomón, la bravura y la piedad de David, las grandes virtudes de Moisés y los patriarcas". ${ }^{15}$ El mismo profeta, en el capítulo once, desarrolla estos atributos de los que estará investido el descendiente de David. La liturgia católica recoge el texto de Isaías aquí grabado, como canto señero de introducción en la fiesta de la Natividad de Jesús, reconociendo de este modo que el niño nacido no es otro que el Mesías o el Emmanuel.

14 Henri Lusseau, "Les hagiographes», Introdution a la Biblie, Tournai, Desclé, 1959, pp. 682 y ss. (texto por Alfred LÄPLE, El Mensaje bíblico en nuestro Tiempo, vol. 2. Madrid, 1967, p. 189).

15 Aa.Vv, Biblia de Jerusalén, Bilbao, 1981, p. 1067, nota 95. Esta es la edición que hemos utilizado. 
En el basamento del lado de la epístola se recoge este otro rótulo: DEVS DILEXIT MVNDVM / VT FILIVM SVVM VNI/GENITVM DARET IO[ANNIS] 3 (Jn $3,16)$. El contenido de este texto tiene su prefiguración veterotestamentaria en el sacrificio de Abraham: "Dios, tentó a Abraham y le dijo: «Abraham, Abraham!» Él respondió: «heme aquí Díjole: "toma a tu hijo, a tu único hijo, al que amas, a Isaac, vete al país de Moria y ofrécele allí en holocausto en uno de los montes, el que yo te diga.»" (Gn 22, 1-2). El versículo aquí grabado en piedra es verdadero eje en el capítulo de la entrevista con Nicodemo, y viene como consecuencia de los dos anteriores que dicen: "Y como Moisés levantó la serpiente en el desierto, así tiene que ser levantado el Hijo del Hombre, para que todo el que crea tenga por él vida eterna". ${ }^{16} \mathrm{Y}$ como aquí se afirma en este epígrafe, tanto amó Dios al mundo que dio a su Hijo único, que se completa del siguiente modo en el texto original: "para que todo el que crea en Él no perezca, sino que tenga vida eterna" (Jn 3, 16).

El concepto del finis mortis y, por ende, la apertura de la nueva vida, la vida eterna, queda patente en este texto joánico, en el versículo anterior al aquí recogido. El que crea en el Hijo del Hombre tendrá vida eterna, puesto que Dios es el dueño de la vida, y este Señor de la vida ha trasmitido este poder a su Hijo, "porque como el Padre resucita a los muertos y les da vida, así también el Hijo da la vida a los que quiere" (Jn 5, 21). Y en la oración de Jesús se recoge este mismo sentir: "Y que según el poder que le has dado sobre toda carne dé también vida eterna a todos los que tú le has dado" (Jn 17, 2). Más aún, el Hijo es la vida, como se manifiesta en el capítulo de la resurrección de

16 Este versículo está tomado del libro de los Números 21, 6-9, donde se hace relación a la serpiente de bronce. Aquí se narra que Yahvé envió contra su pueblo serpientes que mordían a las personas y morían. El pueblo, arrepentido de sus pecados, pidió a Moisés que interceda para que Yahvé apartara de ellos los ofidios. Moisés suplicó por su pueblo ante Él y Este le mandó hacer un abrasador (serpiente alada) y ponerlo sobre un mástil, de tal modo que quien hubiera sido mordido por los ofidios y lo mirara, viviría. Este texto es una clara prefiguración de la crucifixión de Jesús. Al igual que Moisés levantó la serpiente de bronce y todo el que quedaba afectado por el veneno, si miraba a esta serpiente quedaba sanado, así también el Hijo del Hombre sería alzado en la cruz y todo aquel creyente que mirara al Crucificado sería salvado, y tendría la vida eterna. El Hijo del Hombre es la vida y la da a los que crean en Él $(J n$ 5, 24).
Lázaro: “"Yo soy la resurrección. El que cree en mí, aunque muera, vivirá: y todo el que vive y cree en mí, no morirá jamás"” (Jn 11, 25-26); $\mathrm{y}$ en el episodio de las despedidas, le dice al apóstol Tomás: "“Yo soy el Camino, la Verdad y la Vida”" (Jn 14, 5). En el apartado del discurso sobre la obra del Hijo se dice que, "en verdad, en verdad os digo: llega la hora (ya estamos en ella) en que los muertos oirán la voz del Hijo de Dios, y los que la oigan vivirán. Porque como el Padre tiene vida en sí mismo, así también le ha dado al Hijo tener vida en sí mismo" (Jn 5, 24-25). Y esa vida la transmite a todos cuantos creen en Él: "«en verdad, en verdad os digo: el que escucha mi Palabra y cree en el que me ha enviado, tiene vida eterna y no incurre en juicio, sino que ha pasado de la muerte a la vida»" Jn 5, 24).

En el tímpano de la hornacina, cubierto por una venera, en su centro se incluye un ángel pétreo, sustentando una filacteria, proclamando gloria a Dios en las alturas y paz en la tierra a los hombres en quien él se complace: ${ }_{G L}[O R]$ IA IN ALTISSIMIS DEO ET IN T[E]RRA PAX HO[M]I[NI]BVS (Lc 2, 14). Este texto del evangelista san Lucas pertenece al capítulo del nacimiento de Jesús y la visita de los pastores. Previamente a este versículo, el ángel se había aparecido a los pastores que dormían al raso y vigilaban por turno su rebaño; a ellos les dijo: "«No temáis, pues os anuncio una gran alegría, que lo será para todo el pueblo: os ha nacido hoy, en la ciudad de David, un salvador, que es el Cristo Señor, y esto os servirá de señal: encontraréis un niño envuelto en pañales y acostado en un pesebre".". ${ }^{17}$

El ciclo navideño se completa con otros cuatro relieves en la bóveda, sobre el retablo del Nacimiento de Jesús, con las efigies en media figura del rey David y de los tres Magos, enmarcados en círculos decorados con cinco tarjas, incluidos en óvalos de los que penden tarjetas amarradas a las tarjas de la zona baja, que ofrecen epigrafías con textos alusivos a los Salmos y a la Adoración de los Magos, estos últimos tomados del evangelista san Mateo, en su capítulo segundo. Los cuatro personajes quedan identificados por sus correspondientes rótulos en los círculos de las medallas que dicen:

\footnotetext{
17 Este texto tiene su precedente veterotestamentario en el profeta Ezequiel: «entonces el espíritu me levantó y oí detrás de mí el ruido de una gran trepidación: "Bendita sea la gloria de Yahved, en el lugar donde está”.” (Ez 3, 12).
} 
DAVID REX ET PROPH[ETA]; MELCHOR REX; REX GASPAR Y BALTHASAR REX.

El primer personaje a contemplar en este programa iconográfico es David. Con su rostro ladeado hacia su derecha, presenta una amplia y ondulada barba. Como rey de Israel, su cabeza está coronada y porta, como tal, un cetro en su mano derecha, y como músico, sostiene una cítara con su mano izquierda. Esta condición de músico está constatada en varios textos bíblicos, como el que narra su entrada al servicio de Saúl cuando este había perdido el favor de Yahvé: "Dijeron, pues, los servidores de Saúl: "Mira, un espíritu malo de Dios te aterroriza, permítenos, señor, que tus siervos que están en tu presencia te busquen un hombre que sepa tocar la cítara, y cuando te asalte el espíritu malo de Dios, tocará y te hará bien». Dijo Saúl a sus servidores: «buscadme, pues, un hombre que sepa tocar bien y traédmelo». Tomó la palabra uno de los servidores y dijo: "he visto a un hijo de Jesé el belemita que sabe tocar: es valeroso, buen guerrero, de palabra amena, de agradable presencia y Jahved está con él» ... Llegó David donde Saúl y se quedó a su servicio... Cuando el espíritu de Dios asaltaba a Saúl, tomaba David la cítara y la tocaba" (1 S 16, 15-23). En el interior del medallón, un rótulo identifica al personaje: DAVID REX / ET PROPH[ETA]. Estos dos títulos aquí recordados son altamente significativos.

David es el prototipo de rey. Él, en un primer momento, fue reconocido y consagrado como rey de Judá en Hebrón: "David hizo subir a los hombres que estaban con él, cada cual con su familia, y se asentaron en las ciudades de Hebrón. Llegaron los hombres de Judá y ungieron allí a David como rey sobre la casa de Judá" (2 S 2, 3-4). Y siete años más tarde sería ungido rey de Israel: "Vinieron pues, todos los ancianos de Israel donde el rey a Hebrón. El rey David hizo un pacto con ellos en Hebrón, en presencia de Yahved, y ungieron a David como rey de Israel. Treinta años tenía cuando comenzó a reinar y reinó cuarenta años. Reinó en Hebrón sobre Judá siete años y seis meses. Reinó en Jerusalén sobre todo Israel y sobre toda Judá treinta y tres años" (2 S 5, 3-4). Por primera vez en la historia de Israel, se formó un reino bajo un único rey.

Jerusalén fue la nueva ciudad residencial de David, y se convirtió en el centro político y religioso del reino: "David conquistó la fortaleza de Sión que es la Ciudad de David. Y dijo
David aquel día: "Todo el que quiera atacar a los jebuseos que suba por el canal» ... David se instaló en la fortaleza y la llamó Ciudad de David. Edificó una muralla en derredor, desde Milló hacia el interior. David iba medrando y Yahved el Dios Sebaot estaba con él" (2 S 5, 7-10). Con la llegada del Arca de la Alianza a Jerusalén, tal como se narra en el capítulo sexto del Libro Segundo de Samuel, la ciudad de David se convirtió, además, en el centro religioso del nuevo reino, unificándose el culto. La historia de David tiene su eje teológico en la Profecía de Natán, pues aquí se recoge el punto de arranque de las profecías sobre el Mesías, el Hijo de David:"18 "Yahved te anuncia que Yahved te edificará una casa. $\mathrm{Y}$ cuando tus días se hayan cumplido y te acuestes con tus padres, afirmaré después de ti la descendencia que saldrá de tus entrañas, y consolidaré el trono de su realeza. (Él constituirá una casa para mi nombre y yo consolidaré el trono de su realeza para siempre). Yo seré para él padre y él será para mí hijo... Tu casa y tu reino permanecerán para siempre ante mí: tu trono estará firme eternamente" (2 S 7, 11-16).

Pero David, además de rey, fue también salmista y profeta mesiánico. Hasta tiempos no muy lejanos se le atribuyó todo el Libro de los 150 Salmos. Muchos de los salmos, antes de iniciar el texto, indican que pertenecen a David. Como profeta, en el discurso de Pedro a la gente se recoge lo siguiente: "Hermanos, permitidme que os diga con toda libertad cómo el patriarca David murió y fue sepul-

\footnotetext{
8 $\quad$ El Mesías que ha de venir es de linaje davídico. "Saldrá un vástago del tronco de Jesé (el padre de David) y un retoño de sus raíces brotará» (Is 11,1). Jesús es el «Hijo de David", por la sangre, continuador de la dinastía davídica. San Mateo, al inicio de su evangelio, dice: "Libro de la generación de Jesucristo, hijo de David, hijo de Abraham" (Mt 1, 1). El pueblo, así lo reconoce y lo proclama como tal "Hijo de David" en numerosas ocasiones (Mt 9, 27; 12, 23; 15, 22; 20, 30; 21, 9, 15. Mc 10, 47-48. Lc 18, 38-39). Dios dará a Jesús, el hijo que nacerá de María, "el trono de David, su padre" (Lc 1, 32); Jesús es descendiente de David (Jn 7, 42). El reino que Jesucristo viene a establecer, si bien trasciende al propio reino de David, no puede desligarse del reino de Israel, al que David lo constituyó como reino sagrado. Los vecinos de Jerusalén aclamaron a Jesús en su entrada triunfal a esta ciudad, diciendo "bendito el reino que viene de David, nuestro padre" (Mc 11, 10). Sobre estos aspectos, puede consultarse, entre otros, a Evaristo Martín Nieto, "David», en Felipe FernÁndeZ Ramos (dir.), Diccionario de Jesús de Nazaret, Burgos, 2001, p. 265.
} 


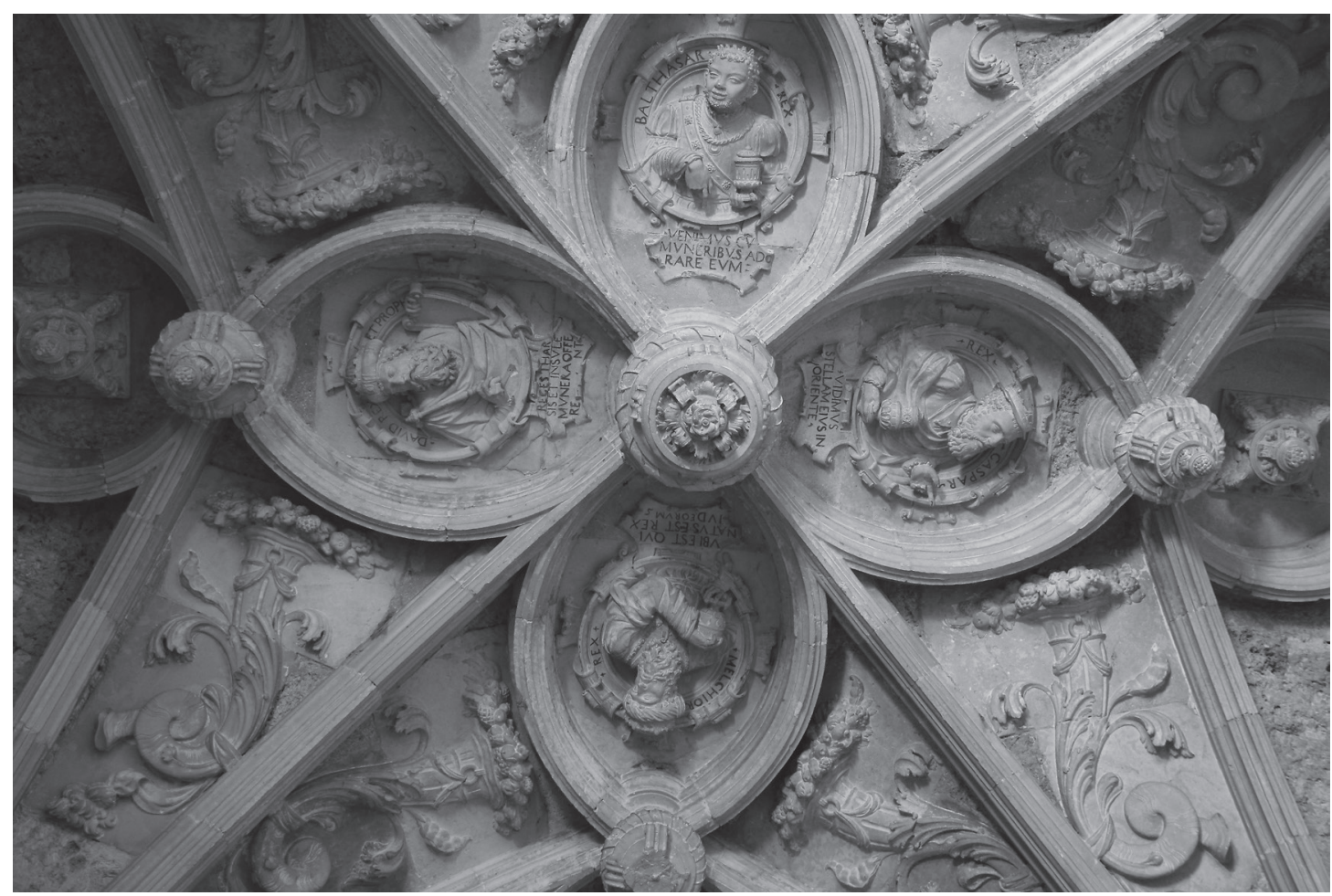

Fig. 5. Claustro de San Marcos de León. Bóveda del ángulo noreste. Medallones de los Reyes Magos y de David. ¿Juan de Angés el Viejo?, hacia 1535-1537.

tado y su tumba permanece entre nosotros hasta el presente. Pero como él era profeta y sabía que Dios le habia asegurado con juramento que se sentaría en su trono un descendiente de su sangre, vio a lo lejos y habló de la resurrección de Cristo, que ni fue abandonado en el Hades, ni su cuerpo experimentó la corrupción. A éste Jesús Dios lo resucitó, de lo cual todos nosotros somos testigos" " Hch 2, 29-32).

Este rey y profeta anuncia aquí, en la cartela que pende del tondo, al rey prometido: REGES THAR/SIS ET INSVL[A]E / MVNERA OFFE/RENT (Sal 72 [71], 10). Ante este rey, los reyes de Tarsis y las islas traerán tributo, y se afirma en el versículo siguiente, "todos los reyes se postrarán ante él y le servirán todas las naciones". Este salmo se refiere a Salomón, en el que se refleja el ideal del rey del futuro. La tradición cristiana ve en este pasaje bíblico el retrato del rey mesiánico, profetizado por Isaías $(9,5)$ y Zacarías $(9,9$ y ss.). En este sentido, de retrato del rey mesiánico, es en el que aquí se aplica, y a la par es la prefiguración de la Adoración de los Reyes Magos que también se efigia acompañando a David, que es quien aquí los presenta, en cuanto rey y profeta.
Los Reyes Magos: «El Rey de los judíos». El astro. La Adoración

Los Reyes Magos se representan en la bóveda, en el tramo sobre el retablo del Nacimiento y puerta de entrada a la iglesia desde el claustro. Se labraron en relieve hasta casi medio cuerpo, insertos en tondos, a su vez incluidos en óvalos. Se atavían con ropas de monarcas, pero a la moda del siglo xvi, muy semejantes en los tres. Cada uno de ellos recoge motivos claves referentes al Salvador escritos en tres cartelas: Melchor, resalta el título de "Rey de los judíos"; Gaspar, pone de relieve el astro que les anunció su nacimiento; y Baltasar, remarca la adoración (proskynésis) que se debe a este Rey.

Melchor presenta su rostro ladeado hacia la izquierda. Una abundante y larga barba ondulada puebla su cara, y cubre su cabeza con un turbante que remata en corona real. La mano derecha sostiene una copa, mientras que con la izquierda, la tapa. Luce en su pecho un collar de cadena. El personaje queda identificado en el interior del medallón: MELCHIOR / REX. Una leyenda en la tarja pendiente del tondo dice: $V B I$ EST OVI / NATVS EST REX / IVD [A] EORVM (Mt 2, 2). El texto que le acompaña, como el de los otros 
reyes, responde a la narración de Mateo, en su capítulo 2, en el que se dice que Jesús había nacido en Belén de Judá, en tiempos del rey Herodes, y que unos Magos provenientes de Oriente se presentaron en Jerusalén preguntando dónde estaba el rey de los judíos que había nacido.

Este primer versículo, como los que se ofrecen a continuación, expresa la misión salvadora ofrecida a los gentiles, a cuyos sabios atrae a su luz. ${ }^{19}$ El título que aquí se le da a Jesús por primera vez, tiene de nuevo una singular importancia en otros dos momentos de su $\mathrm{Pa}-$ sión: cuando fue llevado ante Pilato, quien le preguntó si Él era el rey de los judíos (Mt 27, 11; Mc 15, 2; Lc 23, 3, y Jn 18, 33); y en el momento de la Crucifixión, que le pusieron sobre su cabeza un texto con la causa de su muerte: "Este es Jesús, el rey de los judíos" (Mt 27, 37; Mc 15, 26; Lc, 23, 38). En san Juan, en cambio, se dice que "Pilato redactó también una inscripción y la puso sobre la cruz. Lo escrito era "Jesús el Nazareno, el Rey de los judíos" [INRI]. Esta inscripción la leyeron muchos judíos, porque el lugar donde había sido crucificado estaba cerca de la ciudad; y estaba escrita en hebreo, latín y griego: los sumos sacerdotes de los judíos dijeron a Pilato: "No escribas el Rey de los judíos, sino: Éste ha dicho: Yo soy el Rey de los Judíos». Pilato respondió: "lo que he escrito, lo he escrito" (Jn 19, 19-22).

El rey Gaspar presenta su cuerpo en escorzo, ladeando su rostro hacia el lado izquierdo. Su cabeza coronada se puebla con cabellos cortos con bucles que se prolongan por los laterales de la cara. En la mano derecha porta una copa, mientras que con la izquierda señala con su dedo índice. El personaje queda identificado por la inscripción: REX / GASPAR. Una cartela bajo el tondo reza: VIDIMVS / STELLAM EIVS / IN ORIENTE (Mt 2, 2). En este texto se pone énfasis en la estrella que habían visto en Oriente y que les había guiado durante el camino. En tiempos de Cristo, las gentes creían que había una relación entre el movimiento de los astros y el destino de los hombres y que el nacimiento de los grandes hombres venía acompañado por acontecimientos de orden sideral. En este sentido, habría que interpretar ese astro visto en Oriente, como anunciador del nacimiento del Mesías. El tema de la estrella es rico en teología. En el Antiguo Testamento y en el judaísmo rabínico consideraban a los astros como agen-

19 Biblia de Jerusalén, nota 2, cap. 2, p. 1388. tes divinos que manifestaban los designios y la gloria de Dios (Is 40, 26; 45, 12; Sal 19, 2 y 148, 3). Y esta idea pasó al mundo judeo-cristiano. ${ }^{20}$

El último rey es Baltasar. Otro epígrafe en la parte superior del tondo que lo enmarca, lo identifica: BALTHASAR / REX. Con el cuerpo de frente y el rostro un poco vuelto hacia su derecha, de aspecto joven, presenta rasgos negroides, con labios gruesos, barbas y cabellos cortos y rizados, si bien sus ojos, anómalamente, son rasgados. Se atavía con ropas elegantes, cruzando una banda con pedrería por delante de su pecho donde luce un rico collar de cadena. Su cabeza, como rey, queda coronada. En la mano izquierda lleva una copa, mientras que la derecha, doblada hacia abajo, señala con su dedo índice el texto que se halla en la cartela que pende del tondo: VENIMVS CVM / MVNERIBVS ADO/RARE EVM (Mt 2, 2). ${ }^{21}$ La adoración es la razón y fin último del peregrinaje de los Magos. Es proskynésis al "Rey de los judíos". El verbo griego proskynéin tiene doble significado: por un lado, es el honor que se rinde a una persona por su autoridad; por otro, la adoración que se debe a Dios. Aquí se trata del homenaje a la realeza del recién nacido, en conformidad con el título que ellos le dan: "Rey de los judíos"22. El Evangelio no nos da su identidad, solamente dice: "[...] unos magos que venían de Oriente se presentaron en Jerusalén” (Mt 2, 1). En el siglo IX, en el Liber Pontificalis de Rávena, aparecen los tres nombres por primera vez, recogiendo así un sentir popular antiguo, que deseaba dar culto personificado a estos tres personajes. Sus presuntas reliquias se hallan en la catedral de Colonia.

20 Sobre estos aspectos, véase Gabriel Pérez Rodríguez, $L a$ Infancia de Jesús (Mt 1-2; Lc 1-2), Salamanca, Universidad Pontificia de Salamanca, 1990, p. 215.

${ }_{21}$ En este texto de san Mateo no está recogido cum muneribus. Esta añadición está tomada de san Agustín, en su obra De mirabilibus Sacrae Scripturae, III 4, Jacques Paul Migne, XXXV, 2195. La expresión cum muneribus hace relación a las ofrendas que cada Mago hizo al Niño y que en los relieves de San Marcos de León van incluidas en las copas que portan en sus manos. Gaspar ofrece el oro, Melchor el incienso y Baltasar la mirra. «Jaspar fert aurum, thus Melchior, Baltasar mirram. / Haec quicumque trium secum fert nomina regum / solvitur a morbo Christi pietate caduco" (Louis ReAU, Iconografía del arte cristiano, t. I, vol. 2, p. 251).

22 Véase supra, nota 17, p. 216. 